\title{
A construção da Psicologia Comunitária e sua atuação em zonas rurais
}

\section{The construction of Community Psychology and its contribution in rural and peripheral zones}

\section{Savio Fontes Fragoso*, Alice de Oliveira Monteiro Nascimento, Michele Mariana Vieira Ferreira Santos}

Como citar esse artigo. FRAGOSO, S. F; NASCIMENTO, A. O. M; SANTOS, M. V. F. A construção da Psicologia Comunitária e sua atuação em zonas rurais . Mosaico - Revista Multidisciplinar de Humanidades, Vassouras, v. 12, n. 3, p. 67-72, set./ dez. 2021.

\section{Resumo}

O presente artigo constitui-se uma revisão de literatura, com o intuito de investigar o surgimento da Psicologia Comunitária, bem como sua atuação em territórios rurais e os desdobramentos desta prática. Para tal investigação, foi necessário explorar a formação do psicólogo perante o contexto rural, observando desta forma o despreparo dos profissionais a respeito do trabalho no campo. Além da formação em psicologia, adentramos também o conceito de políticas públicas, visando explorar seu funcionamento e o evidente desmonte delas, no projeto que acreditamos se tratar de uma necropolítica.

Palavras-chave: Psicologia Comunitária; Comunidade; Políticas Públicas; Zona rural.

Nota da Editora. Os artigos publicados na Revista Mosaico são de responsabilidade de seus autores. As informações neles contidas, bem como as opiniões emitidas, não representam pontos de vista da Universidade de Vassouras ou de suas Revistas.

\begin{abstract}
The present article constitutes a literature review, in order to investigate the emergence of Community Psychology, as well as its performance in rural territories and the consequences of this practice. For such an investigation, it was necessary to explore the psychologist's training in the rural context, thus observing the professionals' unpreparedness regarding the work in the field. In addition to training in psychology, we also entered the concept of public policies, aiming to explore their functioning and the evident dismantling of them, in the project that we believe to be a necropolitics.

Keywords: Community Psychology; Community; Public policy; Countryside.
\end{abstract}

\section{Introdução}

Durante o longo percurso da graduação, pouco foi o contato com as disciplinas referentes à Psicologia Comunitária. Apenas nos últimos períodos aconteceram os encontros com os temas relacionados a área instigando, desta forma, a curiosidade e interesse acerca desta vertente da psicologia. Dentre os muitos afetamentos desencadeados na aproximação com a área, foi possível identificar muitas questões emergentes e conflituosas que motivaram a construção do presente artigo.

Das questões que emergiram em meio aos encontros com a área, podemos destacar as poucas menções ao surgimento da psicologia comunitária bem como ao contexto histórico existente na época. Destacamos ainda a dificuldade de compreensão a respeito do conceito de comunidade, sobre o qual iremos abordar algumas vertentes teóricas, sob a ótica de autores que trazem contribuições importantes para a temática que abrange inúmeros conceitos, como comenta Silva \& Simon (2005):

"Tornou-se assim aquilo que Dubar (2002) chama de
palavra-maleta na qual cada um projeta suas crenças,
seus estados de ânimo e suas posições, de maneira
semelhante ao que ocorre com o termo identidade."
(DUBAR, 2002 apud SILVA; SIMON, 2005, p. 39).

Ainda a respeito das questões que serão levantadas aqui, abordaremos as contribuições da psicologia comunitária nos contextos rurais, a formação dos psicólogos perante este território, bem como a análise das políticas públicas, na perspectiva que concerne à Psicologia, buscando entender o funcionamento delas e seus desdobramentos no âmbito das micro e

Afiliação dos autores:

Universidade de Vassouras, Vassouras, RJ, Brasil.

*Email de correspondência: : saviofontes.06@gmail.com 
macropolíticas, que constituem o panorama político nacional.

Desta forma, o objeto de estudo desta pesquisa constitui-se na psicologia comunitária em sua essência, abrangendo seu surgimento, apontamentos, contribuições e desdobramentos, possibilitando um recorte histórico e geográfico, visto que será abordada a relação da psicologia com o território rural.

O objetivo geral deste artigo se dá então pela problematização a respeito do tema, proporcionando ao leitor uma reflexão crítica e novas produções acadêmicas, ao dialogar e discutir os temas aqui contidos, contextualizando o leitor a respeito da construção histórica da psicologia comunitária, apresentando autores e conceitos que versam sobre o termo "comunidade" e explorando nuances do horizonte ético-político da práxis comunitária.

A relevância deste artigo se dá pela importância da Psicologia Comunitária para a sociedade, tendo em vista o cenário político nacional, no qual é possível perceber a presença de uma necropolítica, que pretende sucatear o Sistema Único de Saúde, bem como o Sistema Único de Atenção Básica e os demais dispositivos públicos que favorecem a população brasileira. Desta forma, faz-se cada vez mais necessário evidenciar as contribuições da Psicologia Comunitária e analisar as implicações que dela advém.

\section{História da Psicologia Comunitária}

Para compreender a construção da psicologia comunitária, é necessário analisar seu percurso após o novo paradigma criado em decorrência da crise da psicologia social. Esta crise ocorre na América Latina, durante a década de 70, impulsionada pelos questionamentos dos profissionais acerca da prática da psicologia social.

A crise da Psicologia Social na América Latina se desenvolve a partir do questionamento sobre a repercussão e o impacto dos trabalhos e da produção científica da Psicologia no nosso contexto. Focados neste questionamento e levando essa permanente inquietação de refletir sobre um novo "fazer científico", veio se construindo, principalmente nas últimas três décadas, um novo paradigma em Psicologia Social, compartilhado por várias escolas situadas na América Latina. (NEPOMUCENO et al., 2008, p. 457)

Esse novo paradigma se caracteriza por muitos questionamentos da psicologia, dentre eles a crítica ao caráter passivo do sujeito enquanto ser social e histórico, às práticas objetivistas, e a desconsideração de sua trajetória. A psicologia comunitária na América Latina tem então sua origem a partir da crise da psicologia social, conectando-se desta forma a este novo paradigma (NEPOMUCENO et al., 2008).

O termo "Psicologia Comunitária" passou a ser utilizado na década de 60 e 70, nos EUA, para denominar as práticas que ocorriam fora do contexto clínico individual (SILVA; SIMON, 2005). Tomando força também ao se relacionar com os movimentos comunitários de saúde mental, inspirados no movimento da psiquiatria preventiva. Os movimentos de saúde mental comunitária e psiquiatria preventiva tinham como objetivo prevenir as doenças mentais, ampliando seu atendimento às comunidades, levando pressupostos clínicos para o campo da psicologia comunitária (GONÇALVES; PORTUGAL, 2012).

A partir da década de 80 em meio aos questionamentos em relação à prática psicológica comunitária, a disciplina foi favorecida no Brasil em decorrência da promulgação da nova Constituição Federal, que implementava novas políticas de saúde, como a organização do Sistema Único de Saúde (SUS), as reformas sanitária e psiquiátrica. Diante da redemocratização do país, observa-se um cenário em que a psicologia comunitária direciona críticas ao modelo biomédico, assistencialista e reducionista vigente na época, onde propõe-se alocar a comunidade como um campo homogêneo.

No Brasil, o surgimento da Psicologia Social Comunitária
(PSC) foi atreladoaos movimentos sociais e às reformulações
na área de saúde mental. O processo de pauperização
da população, as Reformas Sanitária e Psiquiátrica e as
políticas sociais pós-Constituição de 1988 (Yamamoto \&
Oliveira, 2010) compõem o cenário em que aconteceram
as primeiras experiências de atuação da Psicologia em
comunidades. (GONÇALVES; PORTUGAL, 2012, p. 564)

Diante do contexto explorado acima, entendese que posteriormente, na década de 90, a psicologia aproximou-se da população menos favorecida, tendo seu campo de atuação ampliado quando passa a inserirse em diversas instituições públicas de saúde, que eram direcionadas às camadas populares da sociedade (GONÇALVES; PORTUGAL, 2012).

Embora o recorte histórico utilizado para remontar a trajetória da psicologia comunitária seja feito sob a ótica do contexto brasileiro, é importante ressaltar que este movimento ocorreu de forma parecida em outros contextos, como afirma Silva e Simon (2005), ao citar Prilleltensky e Nelson (2003):

Este foi um movimento que ocorreu em diferentes partes do mundo de forma similar em sua origem e representação, entretanto, também envolveu as especificidades das diversas realidades dos países e regiões (PRILLELTENSKY; NELSON, 2003 apud SILVA; SIMON, 2012, p. 40).

\section{O conceito de comunidade}

O conceito de comunidade vem sendo discutido ao longo dos anos por muitos teóricos que se propuseram 
a estudar a Psicologia Comunitária, entretanto não é possível ainda afirmar uma definição para o termo. Apresentaremos aqui o conceito sob a ótica de alguns autores, exemplificando a diversidade de sentidos que o termo abrange.

$\mathrm{Na}$ década de 50, a prática da Psicologia no Brasil se aproximava da prática assistencialista, apropriando-se de um conceito de comunidade baseado na delimitação territorial, restringindo o termo a uma perspectiva homogênea, onde os indivíduos pertencentes a um mesmo bairro, cidade ou região integravam uma subjetividade coletiva, dispensando a individualidade de cada sujeito. Segundo Sawaia:

Comunidade era entendida como unidade consensual, sujeito único e homogêneo, lugar de gerenciamento de conflito e de mudanças de atitude. Sua prática visava a união de esforços entre povo e autoridade governamental para melhorar as condições de vida de comunidades e, através delas, integrar a sociedade nacional, construindo a prosperidade do país. E sua delimitação era espacial/ geográfica (SAWAIA, 1996 apud ROCHA, 2012, p. 2).

A partir da década de 80, com as mudanças de perspectiva de atuação da psicologia citadas anteriormente, os indivíduos que integram as comunidades, até então definidas geograficamente, passam a ser vistos como sujeitos de transformação em meio a coletividade. Contudo, após essa modificação ainda existia o impasse entre a nova maneira de olhar os indivíduos da comunidade e a visão homogênea herdada das práticas psicológicas da década de 50 (ROCHA, 2012).

Para além das noções territoriais, o conceito de comunidade é definido por alguns autores como um ideal utópico, que segundo Silva \& Simon (2005), remete a uma sensação boa. As autoras relacionam comunidade ao conceito de saudosismo, explicitando o fato de que alguns profissionais que trabalham com comunidades refletem a imagem de que este trabalho é em prol de causas sociais importantes (SILVA; SIMON, 2005).

As autoras trazem ainda as perspectivas de Bauman (2003) sobre o motivo pelo qual enxergamos a comunidade como algo agradável, e após a reflexão do conteúdo trazido pelo autor, concluem:

É possível que se esteja buscando naquilo que chamamos de comunidade, os valores considerados como "naturais" a ela, como: a solidariedade, a cooperação, o compartilhamento de necessidades e interesses, a justiça social, o fortalecimento das pessoas em relação ao seu poder de decisão e de influenciar a tomada de decisões, a consciência crítica, e a mudança social emancipatória, a possibilidade de construção de concretização de projetos individuais através dos projetos coletivos (SILVA; SIMON, 2005, p. 41).

Entretanto, ainda que existam profissionais com uma visão positiva sobre o termo "comunidade", há outros que o enxergam basicamente como um lugar de falta e de carência, desconsiderando toda e qualquer subjetividade, saberes e desejos dos indivíduos que as compõem. Este é o caso de alguns profissionais atuantes nos programas de saúde, que veem a comunidade apenas como o público a qual é direcionado o programa em questão, não permitindo que os sujeitos atuem na elaboração dele, fator que provoca contradição entre as necessidades reais da comunidade e as necessidades consideradas pelos profissionais de saúde. Esta divergência acarreta na baixa adesão aos programas, que não são capazes de atender realmente as demandas da população.

Existem ainda autores que dividem os significados de comunidade em "tradicionais" e "modernos", referindo-se, respectivamente, a ideia inicial de que a comunidade seria delimitada especificamente por um território, fosse ele espacial ou simbólico, pensamento herdado da época feudal, onde o coletivismo era a forma de vida mais relevante. E, posteriormente, com a entrada da sociedade na era capitalística, tornando vigente o individualismo, a comunidade passa a ser formada por meio de identificação. Tem-se então a ideia de que existe uma possibilidade onde os indivíduos que se identificam uns com os outros, independente da existência de um território previamente delimitado, irão tender a atuar em prol do autocuidado e do compartilhamento, tendo como fator comum a defesa e responsabilidades dos direitos, sobretudo o direito de existir enquanto seres humanos, deixando de lado o pessimismo de uma perspectiva onde os laços e relações desaparecem rapidamente, adotando o caráter de liquidez descrito nas obras de Zygmunt Bauman (LEANDRO, 2008).

\section{O funcionamento das políticas públicas}

Para compreender as discussões acerca das políticas públicas, é necessário entender os âmbitos nas quais elas são desenvolvidas e trabalhadas. Ao contrário do que o senso comum apresenta, as políticas públicas não são influentes apenas nas instâncias governamentais, elas estão presentes nas subjetividades individuais e coletivas da população. Desta forma, elas integram o que chamamos de "micropolítica" e "macropolítica ${ }^{2}$ ", sendo dois âmbitos nos quais a política se desenvolve, entretanto, não podem ser tomados como polos distintos. As micro e macropolíticas se relacionam, construindo uma a outra, compondo todo o cenário político vigente. $\mathrm{O}$ que chamamos de micropolíticas são construções, relações e ações de cada sujeito, não estando presentes apenas ao ato de votar, mas também nos discursos, agenciamentos e escolhas. Todos os seres humanos são constituídos e atravessados pela política, no entanto, em seu estado individual, ela leva o nome de "micropolítica". As macropolíticas, por sua vez, não são um estado "coletivo" da política, mas sim as projeções 
das micropolíticas citadas acima, a política no âmbito macro se dá a partir da individualidade dos sujeitos, ampliando-se de forma a abranger não só uma pessoa, mas a comunidade como um todo.

Já as políticas públicas, que como citado, não se desprendem das micro e macropolíticas, deveriam apresentar-se como legislações e medidas decorrentes das reais necessidades da população, e funcionar em prol delas, servindo ao povo, bem como cita Álvaro Chrispino, a respeito da definição das políticas públicas:

Essa é uma definição importante, porque nos basearemos nela para a construção de nosso texto: a política pública nasce no universo da ciência política e, como tal, deve comportar-se com a mesma dinâmica e mesmo valores que transpassam a política, entendida aqui como a arte de governar ou mesmo como a arte de mediar os interesses contrários. Logo, é certo dizer que criatura (política pública) e criador (política) possuem ligações intrínsecas que devem permitir analogias quase perfeitas. (CHRISPINO; 2016, p. 22)

Desta forma, a via política é então entendida como uma arte, onde o artista tem o papel de gerir a população, bem como de mediar as relações conflitantes que permeiam e caracterizam os grupos sociais. Já como uma via pública, entendemos tudo aquilo que é de domínio do povo, pertencente às comunidades (CHRISPINO, 2016).

Contudo, assim como a maioria das vertentes abordadas no presente texto, as políticas públicas também possuem outros olhares, que são enumerados pelo autor de forma resumida. Dentre as sínteses apresentadas, destaca-se a definição de políticas públicas proposta por Cunha e Cunha (2012), que Chrispino (2016) apresenta:

Entendem política pública como linha de ação coletiva que concretiza direitos sociais declarados e garantidos em lei. É mediante as políticas públicas que são distribuídos e redistribuídos bens e serviços sociais, em resposta às demandas da sociedade. Por isso, o direito que as fundamenta é um direito coletivo e não individual (CUNHA; CUNHA, 2012 apud CHRISPINO, 2016, p. 20).

Esta definição faz uma coerente alusão aos sentidos de comunidade e coletividade abordados até aqui. Remonta a necessidade dos coletivos perante a busca e manutenção de direitos e deveres, que embora não possuam um caráter individual em sua fundamentação, favorecem a cada um dos sujeitos a qual eles contemplam.

No entanto, ainda que o acesso a informações a respeito das políticas públicas seja possível, não é suficiente para que haja forte movimentação popular em defesa delas. Desta forma, pode-se observar um grande esforço de algumas vertentes políticas para desapropriar as classes populares de seus direitos, intermediados por meio das políticas públicas. Percebe- se então, um intencional descuido e desvalorização dos dispositivos públicos, influenciando diretamente a oferta de serviços essenciais para a população, como por exemplo a educação, saúde, assistência básica e segurança. Tal cenário implica profundamente nas práticas profissionais, dentre elas, a prática psicológica, temática principal do presente artigo.

\section{A Psicologia Comunitária no contexto rural}

Antes de iniciarmos a discussão acerca da atuação da psicologia comunitária nas áreas rurais, é importante reconhecer os diferentes conceitos de campo. A primeira concepção sobre o contexto rural refere-se a um espaço visto como contrário às zonas urbanas, onde o desenvolvimento é precário, bem como a condição de vida da população, a figura das pessoas que vivem no campo é caricata, remontando a personagens "caipiras", sujeitos ingênuos, facilmente ludibriados e com pouco estudo, que dependem unicamente da força bruta de trabalho agrícola e agropecuário. Nesta perspectiva, o ideal de crescimento e desenvolvimento se dá a partir do exemplo das áreas urbanas, que são vistas como indispensáveis para a manutenção da vida rural. Ainda nesta concepção, o território rural é composto unicamente por estradas de terra, lavouras, plantações, criações de animais e construções simples.

Entretanto, a segunda concepção, que trabalharemos neste artigo, trata o meio rural como um local de múltiplas construções sociais e vivências, um lugar de luta pela terra, de transformação e criação. Não se trata, então, apenas de um território com limites geográficos, mas de um espaço permeado pela constância da vida (MARTINS, 2010).

Outro aspecto importante para a compreensão da relação entre psicologia e meio rural é a própria formação do psicólogo. A formação acadêmica, de forma geral, apresenta-se muito precária quanto às temáticas abordadas aqui. Embora possua uma abrangência significativa a respeito dos movimentos sociais emergentes, nota-se em grande parte dos casos, o direcionamento das pautas à população das grandes cidades e zonas urbanas, tornando os indivíduos parte dos movimentos e exercitando a potencialidade dos sujeitos envolvidos. Embora seja a proposta correta, é perceptível que o mesmo não se aplica à população rural. À estas pessoas, compete apenas o papel de assistidos pelos profissionais de saúde, situação que decorre do fato de as instituições não preparam devidamente seus alunos para pesquisar e atuar no campo.

$\mathrm{Na}$ formação em psicologia, especificamente, pouco ou mesmo nada é abordado a respeito do trabalho no campo. A pesquisa realizada por Martins (2010) revela que a maioria dos estudantes não teve contato 
na graduação com a prática psicológica em meios não-urbanos, exemplificando como essa parcela da população é ainda negligenciada pela academia, mesmo depois de tantos avanços no campo da psicologia.

Deste modo, os profissionais que começam a atuar neste contexto, muitas das vezes iniciando a jornada no mercado de trabalho, não possuem vasto arcabouço teórico e prático para tal demanda, o que consequentemente acarreta na falta de criticidade, distanciamento profissional e falta de sensibilidade para acolher as questões desta população, dentre outros prejuízos, decorrentes da falta de contato com a realidade rural (SILVA; MACEDO, 2017).

\section{Considerações Finais}

O presente trabalho trata-se de uma revisão bibliográfica, onde foi possível investigar produções científicas acerca dos fenômenos abordados aqui. A partir desta pesquisa pudemos observar alguns recortes históricos sobre temáticas específicas, como o surgimento da disciplina que conhecemos hoje como "Psicologia Comunitária". Para tal, observamos as mudanças que perpassaram a psicologia no Brasil, que se deslocou de uma perspectiva predominantemente experimental, que como muitas profissões e áreas do conhecimento serviu aos horrores do período ditatorial, para então no período pós-ditadura passar a atentar-se às demandas sociais e a debruçar-se sobre o trabalho no âmbito coletivo, surge então neste cenário a disciplina de Psicologia Comunitária, que constitui a principal temática do presente artigo.

Estudando a fundo a Psicologia Comunitária, fezse necessário uma análise acerca dos muitos conceitos de "comunidade" abordados na disciplina. Ainda que as pesquisas tenham sido extensas, não foi possível mencionar todos os conceitos existentes, sendo assim, foram selecionados os que têm melhor relação com as demais temáticas abordadas na pesquisa. Embora os conceitos elaborados na perspectiva capitalista, que definem as comunidades enquanto conjuntos de indivíduos que possuam algum tipo de identificação além do contexto geográfico estejam cada vez mais presentes nos estudos da área, as definições que explicam o termo "comunidade" pela perspectiva espacial ainda são as mais recorrentes, seja no vocabulário popular,

como muitas vezes no científico. Contudo, ainda que não seja uma definição equivocada, esta ótica acaba por desconsiderar as individualidades dos sujeitos, reduzindo-os ao contingente espacial geográfico.

Ao abordar a coletividade, é pertinente que tratemos também a respeito das políticas públicas, que atravessam todas as esferas da sociedade, visto que compõem o cenário político nacional. É preocupante o fato de que mesmo sendo essenciais na manutenção dos direitos e deveres dos cidadãos, as políticas públicas sejam tão desconhecidas e negligenciadas por grande parte da população. Associamos este acontecimento à política de sucateamento dos dispositivos públicos, de descaso com a educação, segurança e condições de saúde das classes médias e baixas da população. É compreensível que este movimento consiste em uma necropolítica ${ }^{3}$, que tem como intuito a desapropriação dos direitos fundamentais da sociedade brasileira.

Por fim, cabe falar a respeito da desvalorização da vida e da cultura rural nas academias de Psicologia. Mesmo em instituições de ensino localizadas em zonas rurais, a cultura enaltecida permanece sendo a da vida urbana, existindo muito pouco ou nenhum contato com teorias e materiais destinados ao trabalho no campo. A cultura urbana é muitas vezes definida como um ideal de desenvolvimento que deve ser alcançado pelas populações rurais, desconsiderando todas as formas de organização e potencialidades presentes nos meios rurais. Entende-se então a população rural como "carente" ou "vulnerável", que deve depender dos subsídios das populações urbanas para a manutenção de sua existência. Entretanto, mesmo que exista uma organização diferente nas populações urbanas e rurais, não faz com que esta ou aquela sejam deficitárias. Contudo, a falta de contato prévio com a teoria e experiência do trabalho em zonas rurais faz com que os profissionais da psicologia não estejam preparados de fato para a prática nestes contextos, o que os leva a atuar de forma pouco eficaz nestes territórios e a reproduzir discursos reducionistas a respeito da população rural.

\section{Notas}

1. Investiga as relações de forças articuladas aos agenciamentos desejantes no campo social, seja nos grandes ou pequenos conjuntos, ou melhor, compreende as forças como desejo. Por exemplo, pode-se realizar uma micropolítica da família, bem como uma micropolítica do Estado (HUR, 2019, p.71-72).

2. A macropolítica corresponde ao molar, à política instituída e estratificada, ao Estado, partidos políticos e conjuntos sociais instituídos. Busca analisar as relações de poder e embates nas instâncias dos processos decisórios. Referese à concepção tradicional de política com suas categorias estabelecidas (HUR, 2019, p. 71).

3. Necropolítica refere-se à criação de mundos da morte, onde a partir de instrumentos de controle populacionais, decide-se quem vive e quem morre, e torna-se a morte de uma parcela específica de seres humanos aceitável. A noção de biopoder, neste contexto, é insuficiente para explicar a subjugação da vida ao poder da morte. Nesta "política de morte", enormes populações são submetidas a condições incompatíveis com a vida, tendo atribuída a elas o status de "mortos-vivos" (MBEMBE, 2016).

\section{Referências}

BAUMAN, Zygmunt. Comunidade: A busca por segurança no mundo atual. Tradução de Plínio Dentzien. 1ª Ed. Rio de Janeiro: Jorge Zahar, 2003.

CHRISPINO, Alvaro. Introdução ao estudo das políticas públicas: Uma visão interdisciplinar e contextualizada. 1. ed. Brasil: FGV, 2016. 256 p. v. 1. 


\section{ISBN 978-85-225-1780-0}

GONÇALVES, Mariana Alves; PORTUGAL, Francisco Teixeira. Alguns Apontamentos sobre a Trajetória da Psicologia Social Comunitária no Brasil. PSICOLOGIA: CIÊNCIA E PROFISSÃO, [s. 1.], n. 32, p.

138-153, 2012. Disponível em: https://www.scielo.br/pdf/pcp/v32nspe/ v32speca10.pdf. Acesso em: 25 fev. 2021.

GONÇALVES, Mariana Alves; PORTUGAL, Francisco Teixeira. Análise histórica da psicologia social comunitária no Brasil. Psicologia \& Sociedade, [s. 1.], v. 28, n. 3, p. 562-571, 2016. DOI http://dx.doi. org/10.1590/1807-03102016v28n3p562. Disponível em: https://www.scielo. br/pdf/psoc/v28n3/1807-0310-psoc-28-03-00562.pdf. Acesso em: 25 fev. 2021

HUR, Domenico Uhng. Psicologia, política e esquizoanálise. 2. ed. rev. Campinas: Alínea, 2019. 194 p. ISBN 978-85-7516-864-6.

LEANDRO, Janine Barreira. Comunidade: Uma Reflexão a Partir de Zygmunt Bauman. Kairós: Revista Acadêmica da Prainha, Ceará, v. 1, p. 156-162, 2008. Disponível em: https://docplayer.com.br/23864143Comunidade-uma-reflexao-a-partir-de-zygmunt-bauman.html. Acesso em: 25 fev. 2021.

MARTINS, Alberto Mesaque et al . A formação em Psicologia e a percepção do meio rural: um debate necessário. Psicol. Ensino \& Form., Brasília , v. 1, n. 1, p. 83-98, abr. 2010 . Disponível em http://pepsic.bvsalud.org/scielo.php?script=sci_arttext\&pid=S2177$20612010000100008 \& \operatorname{lng}=$ pt\&nrm=iso. Acesso em: 25 fev. 2021.

MBEMBE, Achille. Necropolítica: Biopoder soberania estado de exceção política da morte. Arte \& Ensaios, [s. 1.], ed. 32, p. 122-151, Dezembro 2016. Disponível em: https://revistas.ufrj.br/index.php/ae/article/view/8993/7169. Acesso em: 10 maio 2021.

NEPOMUCENO, Léo Barbosa et al. Por uma psicologia comunitária como práxis de libertação. PsiCo, Porto Alegre, v. 39, n. 4, p. 456-464, 2008. Disponível em: https://revistaseletronicas.pucrs.br/ojs/index.php/ revistapsico/article/view/3532/3836. Acesso em: 25 fev. 2021

ROCHA, Tatiana Gomes da. Discutindo o conceito de comunidade na psicologia para além da perspectiva identitária. Global Journal of Community Psychology Practice, [s. 1.], v. 3, n. 4, 2012. Disponível em: https://www.gjcpp.org/pdfs/2012-Lisboa-063.pdf. Acesso em: 25 fev. 2021.

SILVA, Kátya de Brito e; MACEDO, João Paulo. Inserção e trabalho de psicólogas/os em contextos rurais: interpelações à psicologia. Revista de Psicologia, Fortaleza, v. 8, n. 2, p. 146-154, 2017. Disponível em: http:// www.periodicos.ufc.br/psicologiaufc/article/view/11886. Acesso em: 25 mar. 2021.

SILVA, Rosalina Carvalho da; SIMON, Cristiane Paulin. Sobre a diversidade de sentidos de comunidade. PsiCo, Porto Alegre, v. 36, n. 1, p. 39-46, 2005. Disponível em: https://revistaseletronicas.pucrs.br/ojs/index. php/revistapsico/article/view/1373/1073. Acesso em: 25 fev. 2021. 